\title{
Teresinha Soares, Marta Minujín e Teresa Burga: conexões transnacionais sul-americanas sob a perspectiva de gênero
}

\author{
Carolina Vieira Filippini Curi ${ }^{1}$
}

\begin{abstract}
Resumo: O artigo centra-se na análise de obras produzidas nos anos 1960 e no início dos anos 1970 por três artistas sul-americanas: a brasileira Teresinha Soares, a argentina Marta Minujín e a peruana Teresa Burga. As artistas tiveram em comum, além da associação à pop arte e à nova figuração no período, o interesse em discutir a sexualidade e a objetificação feminina e os estereótipos de gênero. A análise de suas obras, algumas delas marginalizadas por décadas, permite não somente uma compreensão mais acurada da produção artística do período, mas do próprio contexto histórico e social no qual estavam inseridas, além dos processos de exclusão e de formação da identidade feminina.
\end{abstract}

Palavras-chave: mulheres artistas, arte sul-americana, conexões transnacionais.

\section{Teresinha Soares, Marta Minujín e Teresa Burga: transnational connections in South America from a gender perspective}

\begin{abstract}
The article focuses on the analysis of artworks produced in the 1960s and early 1970s by three South American artists: the Brazilian Teresinha Soares, the Argentinian Marta Minujín, and the Peruvian Teresa Burga. These artists shared, besides their association with pop art and the new figuration of the period, an interest in discussing the female sexuality, the objectification of women, and gender stereotypes. The analysis of their works, some of them marginalized for decades, allows not only a more accurate understanding of the artistic production of the period, but of the historical and social context in which they were inserted, in addition to the processes of exclusion and formation of female identity.
\end{abstract}

Keywords: women artists, South American art, transnational connections.

Artigo recebido em: $31 / 08 / 2021$

Artigo aprovado em: 30/11/2021

\footnotetext{
${ }^{1}$ Doutoranda em Artes Visuais (PPGAV) UNICAMP, com projeto apoiado pela CAPES (Processo 88887.475654/2020-00). E-mail: carol.filippini@gmail.com.
}

ORCID: https://orcid.org/0000-0002-0442-2329. 
A busca por histórias alternativas e pela recuperação de vozes subalternizadas que se deu a partir de meados da década de 1960 colocou em xeque diversas disciplinas, dentre elas a história e, mais especificamente, a história da arte. A vaga feminista dos anos 1960, que se estabeleceu a partir do questionamento sistemático do status quo e da universalização da masculinidade, os estudos pós-coloniais desenvolvidos de forma mais aprofundada a partir da publicação, em 1978, do livro Orientalismo - O Oriente como invenção do Ocidente, de Edward Said, aliados ao processo de globalização a partir dos anos 1980 e às políticas de incentivo ao multiculturalismo, tiveram um papel chave no processo de transformação da história enquanto disciplina. Campos da historiografia contemporânea, como a História das Mulheres e a História Oral, por exemplo, passaram a compartilhar uma mesma preocupação em resgatar narrativas suprimidas e renovar as leituras de momentos históricos passados. Assim, a história da arte também vem gradualmente passando por uma revisão a partir da perspectiva de gênero, o que permitiu lançar luz a artistas e produções até então marginalizadas.

Porém, se já na década de 1970 "diferentes disciplinas do saber incorporaram a perspectiva feminista que lhes permitiu "descobrir" novos objetos de estudo que até então tinham permanecido invisíveis" (VICENTE, 2012, p. 20), foi somente a partir do final dos anos 1990 que a produção de mulheres artistas da América Latina passou a ser estudada mais a fundo. ${ }^{2}$ Assim, apesar do crescente número de publicações e exposições que tratam da produção artística feminina latino-americana, muitas lacunas permanecem em aberto. Diversas artistas e produções carecem de análise e esse amplo campo de investigação ainda requer um significativo investimento de estudo. Dentre estas lacunas está a produção feminina da pop arte e da nova figuração produzida na América do Sul nos anos 1960 e início dos anos 1970.

\footnotetext{
${ }^{2}$ Dentre as publicações e exposições dedicadas à produção de mulheres da América do Sul lançadas a partir dos anos 1990, destacam-se: a mostra Latin American Women Artists, 1915-1995, com curadoria de Geraldine P. Biller, no Museu de Arte Milwaukee, em 1995, a exposição Manobras Radicais, com curadoria de Heloisa Buarque de Holanda e Paulo Herkenhoff, no Centro Cultural Banco do Brasil em 2006, o ensaio Gênero y Feminismos: Perspectivas desde América Latina, de Andrea Giunta, de 2008, o Programa Mujeres Artistas do Museo de Arte Latinoamericano de Buenos Aires, em 2016, e a exposição Mulheres Radicais: arte latino-americana, 1960-1985, com curadoria de Cecilia Fajardo-Hill e Andrea Giunta, inaugurada em 2017 no Hammer Museum, exibida também na Pinacoteca de São Paulo no segundo semestre de 2018.
} 
Muitas artistas sul-americanas ligadas a essas correntes foram recentemente retomadas e reavaliadas por pesquisadoras e pesquisadores da América do Sul e de outros espaços, e apresentadas em exposições internacionais sobre a chamada Pop Global e sobre a produção feminina latino-americana, como Mulheres Radicais: arte latino-americana, 1960-1985, curada por Cecilia Fajardo-Hill e Andrea Giunta no Hammer Museum em 2017, também exibida na Pinacoteca de São Paulo em 2018, The World Goes Pop, com curadoria de Jessica Morgan e Flavia Frigeri, inaugurada na Tate Modern, em Londres, em 2015, e International Pop, com curadoria de Darsie Alexander e Bartholomew Ryan, realizada no Walker Art Center, Minneapolis, em 2015. Estas pesquisas e mostras trouxeram à tona obras que, embora reconhecidas em seu local e período de produção, tiveram uma circulação limitada, tendo sido pouco estudadas posteriormente. Uma análise mais aprofundada e a partir de uma perspectiva comparada dessas produções se faz necessária, portanto, para que se possa lançar luz a aspectos até então negligenciados acerca dessas obras e das trajetórias dessas artistas. Além disso, a retomada dessas produções permite não somente uma melhor compreensão da produção artística do período, mas do próprio contexto histórico e social e dos processos de exclusão e de formação da identidade feminina.

Dessa maneira, este artigo realizará um estudo comparativo de produções dos anos 1960 e início dos 1970 de três artistas sul-americanas ligadas à arte $p o p$ e à nova figuração: a brasileira Teresinha Soares, a argentina Marta Minujín e a peruana Teresa Burga. Jovens e iniciando suas carreiras nos anos 1960, elas têm em comum, além da participação em "movimentos" conectados a um retorno à figuração e à representação do meio urbano e dos efeitos da sociedade de consumo nos modos de vida, o interesse em discutir a sexualidade e a objetificação feminina. Essas artistas foram, via de regra, abordadas sob a perspectiva de suas trajetórias individuais, sendo raramente trabalhadas em comparação e poucas vezes consideradas como um grupo específico sujeito a conjunturas particulares, derivadas de sua condição de gênero. Assim, muitas perguntas permanecem, por exemplo, com relação aos diálogos possíveis entre suas produções, às suas estratégias profissionais, às identidades de grupo, entre outras. Este estudo está, portanto, em consonância com trabalhos recentes que se preocupam em repensar a história da arte dentro de uma estrutura transnacional, 
"posicionando a análise formal de obras individuais dentro de uma discussão mais ampla sobre local, contexto e intercâmbio cultural" (GREET, 2016, p. 145).

As produções das três artistas, realizadas em um momento de reefervescência do movimento feminista nos Estados Unidos e na Europa, mas imediatamente anterior à arte abertamente feminista e à consolidação das pautas feministas em seus países, e em um período marcado pelas ditaduras militares na América do Sul, nos informam sobre as problemáticas de gênero e a situação social do período. Suas obras, assim como as de outras mulheres sul-americanas da época, abordaram temas como a subjetividade e a sexualidade femininas, a objetificação da mulher, as noções aceitas de feminilidade e as tensões entre o espaço público e o privado. Elas nos permitem refletir sobre a formação das noções aceitas de feminilidade e da identidade feminina, forjadas em um embate entre a maneira como essas mulheres se enxergavam e o que buscavam e as imagens de mulheres propagadas pelos meios de comunicação e pelos governos conservadores e repressivos.

É importante ressaltar, porém, que as três artistas evitam uma conexão direta com os feminismos, e, ainda, que o termo feminista possuía uma conotação pejorativa nesses países em tal período. No Brasil, o Golpe Militar de 1964 depôs o presidente democraticamente eleito João Goulart e deu início à ditadura que perdurou até 1985. As associações feministas praticamente desapareceram com o golpe, voltando a tomar impulso somente a partir de 1975, com a instauração do Ano Internacional da Mulher, por iniciativa da $\mathrm{ONU}^{3}$. Já a Argentina, após a deposição de Juan Domingo Perón em 1955, passou por sucessivos golpes militares, tendo, entre 1976 e 1983, seu último e mais violento período de regime ditatorial, comandado pelo general Jorge Rafael Videla. Embora tenham surgido grupos e associações como a Unión Feminista Argentina no início dos anos 1970, eles foram reprimidos pelo regime de 1976 e só voltaram a se estabelecer no período de redemocratização. No Peru, a ditadura militar instaurada pelo general Juan Velasco Alvarado em 1968 perdurou até 1980. De acordo com

\footnotetext{
${ }^{3}$ Foi a partir daí, como ressalta Maria Amélia Teles, que "as brasileiras retomaram o movimento feminista" (TELES, 2017, p. 25) e que as "ideias feministas de exigir igualdade de direitos e questionar o papel de submissão da mulher vão começar a ter ressonância junto à opinião pública” (TELES, 2017, p. 96). Teles destaca que, embora a iniciativa da ONU tenha sido vista com desconfiança pelas norte-americanas e europeias, "no Brasil ela cai como uma luva: excelente instrumento legal para fazer algo público, fora dos pequenos círculos das ações clandestinas". (TELES, 2017, p. 96).
} 
Helen Orvig (2014), eram poucos os grupos e reuniões de mulheres centrados na discussão dos direitos e da autonomia feminina nos anos 1960, sendo que, somente a partir da segunda metade da década de setenta é que surge um maior número de associações de mulheres, e as pautas feministas passam a ser discutidas de maneira mais ampla. ${ }^{4}$

Dentro desses cenários repressores, o feminismo foi constantemente apresentado como um movimento de mulheres frustradas e pouco femininas. O termo "feminista" ganhou um teor pejorativo e boa parte das intelectuais e das artistas sul-americanas do período não se identificava com o termo. ${ }^{5}$ Isso não quer dizer, porém, que as artistas não tenham abordado, de maneira mais ou menos direta, muitas das questões que foram centrais para a chamada segunda vaga feminista. Afinal, apesar do conservadorismo e da repressão presente em seus países, elas viveram em um contexto que também foi marcado pela expansão do sistema educacional, pela entrada de um maior número de mulheres de classe média no mercado de trabalho, pela maior liberdade para circular pelo espaço público, pela chegada ao mercado da pílula anticoncepcional, bem como pela ascensão da TV e da publicidade, muito voltadas ao público feminino. As mulheres experimentariam, assim, transformações significativas em seu cotidiano, no âmbito público e privado, o que as levou "a questionar proibições relacionadas à sexualidade, à família e à participação política” (MELENDI, 2018, p. 229). As artistas ligadas

\footnotetext{
${ }^{4}$ Helen Orvig, em seu texto para o seminário 25 Años de Feminismo en el Perú: Historia, confluencias y perspectivas, organizado em 2014 pelo Centro de la Mujer Peruana Flora Tristán, relata: "Nossa busca nos anos 60 se distinguiu muito do clima de entusiasmo trazido ao Peru pelas holandesas e Kate Young em 1978. Nossa busca foi solitária, vacilante e dolorosa. Éramos poucas as que nos reuníamos naquela época e, além disso, todas diferentes umas das outras (...). (ORVIG, 2014, p. 18). Tradução da autoria, no original: "Nuestra búsqueda en los años 60 se distinguió mucho del ambiente de entusiasmo traído al Perú por las holandesas y Kate Young en 1978. La nuestra fue una búsqueda solitaria, titubeante, dolorosa. Éramos pocas las que nos reuníamos en esa época y, además, todas diferentes las unas de las otras" (ORVIG, 2014, p. 18).

${ }^{5}$ Como ressalta Talita Trizoli em sua tese de doutorado Atravessamentos Feministas: um panorama de mulheres artistas no Brasil dos anos 60/70, a maior parte das artistas brasileiras do período resistiu ao uso do termo feminista, pois o enxergava como um rótulo que significaria uma "restrição à sua identidade como artista" (TRILOZI, 2018, p. 59). Entre as diversas artistas entrevistadas pela autora, é recorrente um discurso que afirma que a questão de gênero não teria influenciado suas circulações e inserções, e que a discussão do movimento feminista não chegava para elas como algo relevante no período. A mesma resistência pode ser encontrada entre as artistas argentinas. Como discute Connie Butler, em seu texto Monumentos caidos: o continuum feminista, presente no catálogo Mulheres Radicais: arte latino-americana, 1965-1980, Minujín não se identificou com uma posição feminista e, para a autora, "trabalhando na Argentina, Minujín tinha pouco contexto para que pudesse chamar sua prática de feminista, mesmo com o surgimento de manifestações feministas em outros lugares" (BUTLER, 2018, p. 43) e, além disso, "no contexto patriarcal do meio artístico argentino da época, a reivindicação do feminismo teria levado a uma desvalorização de seu status de 'artista' para além de sua condição de artista mulher" (BUTLER, 2018, p. 43).
} 
à arte $p o p$ e à nova figuração desses países, ao se voltarem para o registro do cotidiano e da vida urbana, em obras muitas vezes autorreferenciais, retrataram, assim, essas novas vivências e os embates das mulheres da época. Elas abordaram as relações amorosas e sexuais, a representação da mulher pela publicidade, o cinema e a mídia em geral, a relação com o espaço doméstico, entre outras problemáticas que eram compartilhadas pelas mulheres de classe média.

Assim, em um contexto de grandes mudanças no cotidiano das mulheres, não será, portanto, uma coincidência, como ressalta Talita Trizoli, a "evidente presença da 'questão feminina' nos trabalhos das artistas mulheres dessa época, pois elas se encontravam à mercê de indagações subjetivas do gênero, apesar de certa relutância em nomear tais questões pelo epíteto feminista" (TRIZOLI, 2018, p. 38). Dessa forma, embora em nosso período e local de análise, a maior parte das artistas "não se chamasse de feminista, elas examinaram, com intensidade, a subjetividade e a situação problemática da mulher na sociedade e como ser condicionado pela biologia e pela cultura" (GIUNTA, 2018, p. 29). Podemos pensar, portanto, que nas obras que serão aqui analisadas, se as pautas feministas não são incorporadas de maneira consciente, elas aparecem, como destaca Trizoli, em condição de atravessamento ou de infiltração (TRIZOLI, 2018)

As questões relacionadas à representação do corpo, à objetificação e à sexualidade femininas serão representadas de maneira direta nas obras da brasileira Teresinha Soares. Nascida em 1937, em Araxá, Minas Gerais, Soares produziu um grande número de pinturas, desenhos, objetos, instalações e performances que tiveram ampla repercussão nos anos 1960 e 1970. A artista, ligada à Nova Figuração brasileira, discutia a opressão vivida pelas mulheres, a subjetividade e a sexualidade femininas, e usava o erotismo, ainda, como instrumento por meio do qual examinava questões relacionadas aos "costumes morais, o consumo e a política" (MARTINS; PEDROSA, 2017, p. 13). Soares, que vivia e trabalhava em Belo Horizonte, parou de produzir em 1976, e suas obras circularam muito pouco após o final de sua carreira, sendo retomadas apenas nos últimos anos. A obra da artista permaneceu desconhecida por décadas, como ressaltam Heitor Martins e Adriano Pedrosa, "mesmo nos circuitos mais bem 
informados da arte contemporânea brasileira (...) assim como a de muitas outras artistas que trabalharam nos anos 1960 e 1970" (MARTINS; PEDROSA, 2017, p. 14).

Uma das características centrais em suas obras, algo também presente em obras de Marta Minujín e Teresa Burga, foi a representação constante do corpo nu ou seminu da mulher (e também, por vezes, do homem) em cenas que remetem ao sexo e ao erotismo. Isso não será, é claro, uma característica particular das produções da $p o p$ e da nova figuração, nem exclusiva das artistas sul-americanas. Nos anos 1960, surgiram novas maneiras de representar o corpo e, junto a elas, "uma virada iconográfica radical das tradições estabelecidas" (GIUNTA, 2018, p. 29). Em um contexto de discussões acerca dos diferentes sistemas de controle do corpo e da sexualidade abordados, por exemplo, por Michel Foucault e pela psicanálise, o corpo "acometido por estereótipos, ou até mesmo por tabus ligados a estruturas patriarcais do modernismo heterossexual e normativo, passou a ser questionado e investigado de modo intenso." (GIUNTA, 2018, p. 29). Se o corpo feminino foi constantemente representado por homens e mulheres da pop e da nova figuração, tanto na América do Sul quanto na Europa e nos Estados Unidos, nas produções femininas ele apareceu especialmente como um "meio para realizar dramatizações de gênero específicas e mostrar novas maneiras de sair do beco sem saída da sociedade patriarcal do pós-guerra" (STIEF, 2011, p. 82) ${ }^{6}$. A representação do corpo foi realizada, assim, por muitas mulheres artistas, como uma maneira de se apropriar de seus desejos e de seus corpos, bem como de discutir a sexualidade feminina.

Isso pode ser visto nas obras da série Homenagem a Caetano Veloso ${ }^{7}$, de 1968, uma das mais eróticas de Soares. A artista representa fragmentos do corpo feminino, como seios, vagina, boca, pernas, mãos e pés, que se misturam e interagem com elementos fálicos, como pênis e dedos agigantados. A abstração do corpo é utilizada, nessas e em outras obras de Soares, como uma maneira de evitar a objetificação da mulher (FAJARDO-HILL , 2017), ao mesmo tempo que a abstração, a fragmentação e a representação do corpo sem rosto são

\footnotetext{
${ }^{6}$ Tradução da autora, no original: “(...) site for carrying out gender specific role-plays, and show new ways out of the blind alley of the post war patriarchal society" (STIEF, 2011, p. 82).

${ }^{7}$ Os títulos das obras dessa série fazem referência a canções de Caetano, que influenciou muitos artistas da época.
} 
também empregadas com o intuito de denunciar a objetificação do corpo feminino pela mídia de massa e pela sociedade da época. As serigrafias da série, embora explorem a abstração, mostram os órgãos sexuais de maneira bastante direta, possuindo um intenso teor erótico, transgressor para a época.

Na serigrafia Ele e ela [imagem 1], um pênis, em roxo, aparece no centro da pintura, em destaque, representado em um tamanho desproporcional, com o elemento fálico aparecendo monumentalizado. O falo é abraçado por fragmentos de um corpo feminino, que formam um ser desfigurado, e vai de encontro a uma boca, ou a uma vagina dentada, em referência à ideia da vagina castradora que revelava o pavor dos homens frente ao que buscavam reprimir, jogando, assim, com mitos relacionados à feminilidade.

\section{Imagem 1 - Ele e ela}

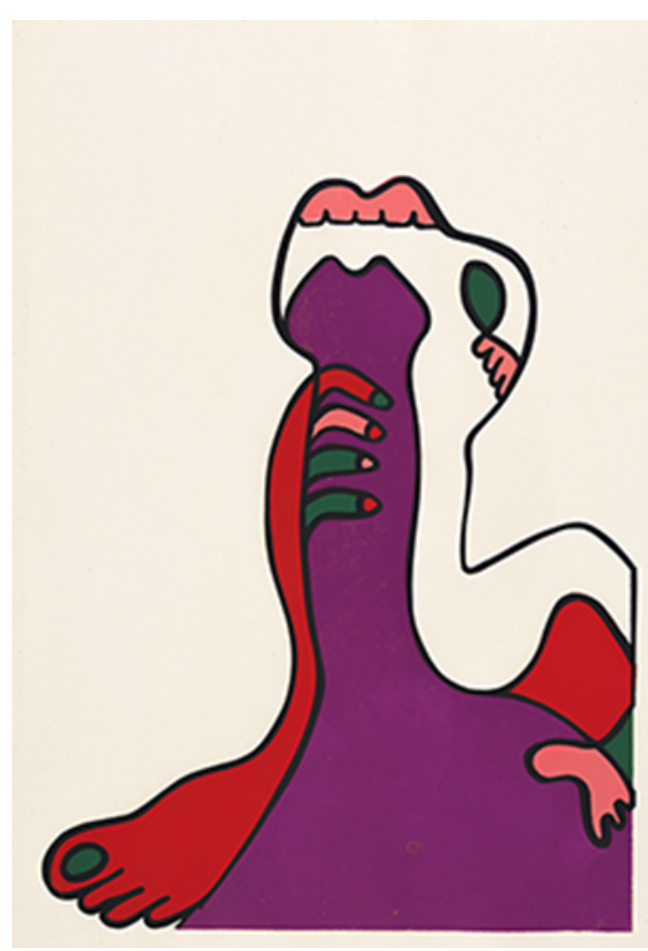

Teresinha Soares, da série Homenagem a Caetano Veloso, 1968. Serigrafia sobre papel, 47 x $32 \mathrm{~cm}$. Coleção da artista, Belo Horizonte. Foto: Jorge Bastos. 
Na obra Viver é preciso II [imagem 2], da mesma série, vemos o seio, a cintura e as pernas de uma mulher sem rosto, e também um pênis, que parece entrar ou sair de suas pernas. A obra mostra uma união de partes do corpo feminino e do masculino e sugere uma cena de sexo a dois, ou de masturbação. Soares trabalha, dessa forma, vários temas que eram considerados tabus na época, e suas imagens eróticas confrontavam a sociedade tradicional católica mineira.

\section{Imagem 2 - Viver é preciso II}

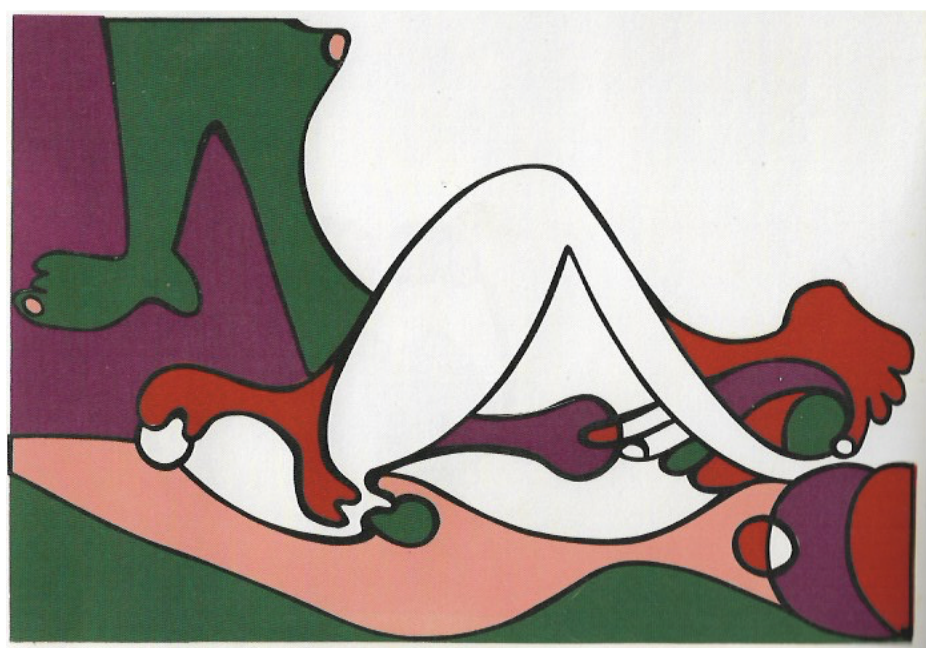

Teresinha Soares, da série Homenagem a Caetano Veloso, 1968.

Serigrafia sobre papel, 33 x $49 \mathrm{~cm}$. Coleção da artista, Belo Horizonte. Foto: Jorge Bastos.

As obras da série discutem, assim, a liberdade sexual, o desejo e o prazer femininos, em confronto com os ideais conservadores da sociedade brasileira, que vivia, em 1968, um período de endurecimento da ditadura militar. Soares posiciona a mulher como ser desejante, com pleno direito sobre seu corpo e sua sexualidade, em uma postura política de enfrentamento que escandalizou a sociedade tradicional e católica da época. Além disso, a representação de órgãos sexuais femininos e masculinos unidos, como parte de um mesmo corpo, poderia remeter ainda a um sonho que a artista relatava ter, no qual ela era uma hermafrodita. A figura da hermafrodita é reveladora das problemáticas de gênero, pois ela “permite igualmente interrogar a propósito das modalidades de identificação do indivíduo em 
uma sociedade e, mais genericamente, as tensões no Estado moderno entre as liberdades individuais e o controle social" (HOUBRE, 2009, p.20). A questão do hermafroditismo pode ser pensada, portanto, como uma maneira de elaborar a questão da construção da feminilidade e da masculinidade, evidenciando como estas são construções sociais que estabelecem o papel e o lugar do indivíduo na sociedade.

O erotismo e a reivindicação da liberdade sexual também estiveram presentes em obras da argentina Marta Minujín. Nascida em Buenos Aires, em 1943, a artista, ainda hoje em franca atividade, alcançou grande consagração na Argentina e internacionalmente, e sua produção ficou conhecida nos anos 1960 como "uma resposta latino-americana à Pop" (BARNITZ, 1966, s/n) ${ }^{8}$. Embora tenha se identificado com o rótulo pop, sua produção do período possui um caráter multidisciplinar, combinando aspectos da arte pop com o happening e a arte conceitual. Além de discutirem os códigos e explorarem as ferramentas dos meios de comunicação de massa, muitas de suas obras abordaram a questão do erotismo e da libertação sexual.

A série Frozen Sex foi produzida durante sua estadia em Washington, em um ano marcante para o movimento feminista americano com a legalização do aborto em todos os estados do país. Em telas de grandes proporções, Minujín traz à frente os órgãos sexuais em close, monumentalizados, em um movimento semelhante ao de Teresinha Soares, embora com um resultado estético diferente. Em obras como sem título, 1974 [imagem 3], vemos um grande falo frente a um fundo com massas de cores abstratas que representam, talvez, duas pernas em vinho e uma vagina em rosa escuro, em contato com o pênis. Em obras como sem título, 1973-1974 [imagem 4], vemos os fragmentos de pernas, uma vagina e um pênis, sob um fundo com massas abstratas.

As obras revelam frontalmente os órgãos sexuais, sendo que a representação direta, e com certa frieza do sexo e do erotismo, foi relacionada, por Francisco Lemus, a uma atitude cool e despersonalizada de parte dos artistas da pop norte-americana (LEMUS, 2018).

\footnotetext{
${ }^{8}$ Marta Minujín foi assim apresentada por Jacqueline Barnitz, no artigo intitulado 'A Latin Answer to Pop', na Arts Magazine, em junho de 1966. O título do artigo pode ser considerado redutor, colocando Minujín como uma artista que simplesmente responde a tendências estrangeiras.
} 
Minujín relata que as cores utilizadas nas pinturas são uma referência à coloração de salsichas, presunto e carne congelada (MINUJÍN, 2018, s/n). Os falos e vaginas são apresentados, assim, como objetos que poderiam ser encontrados em prateleiras de supermercados, como comidas enlatadas ou comidas congeladas - Frozen Sex/Sexo Congelado, pronto para consumo. Esses corpos, fragmentados e sem rosto, apareceriam, assim, como objetos de consumo. 


\section{Imagem 3 -Sem título}

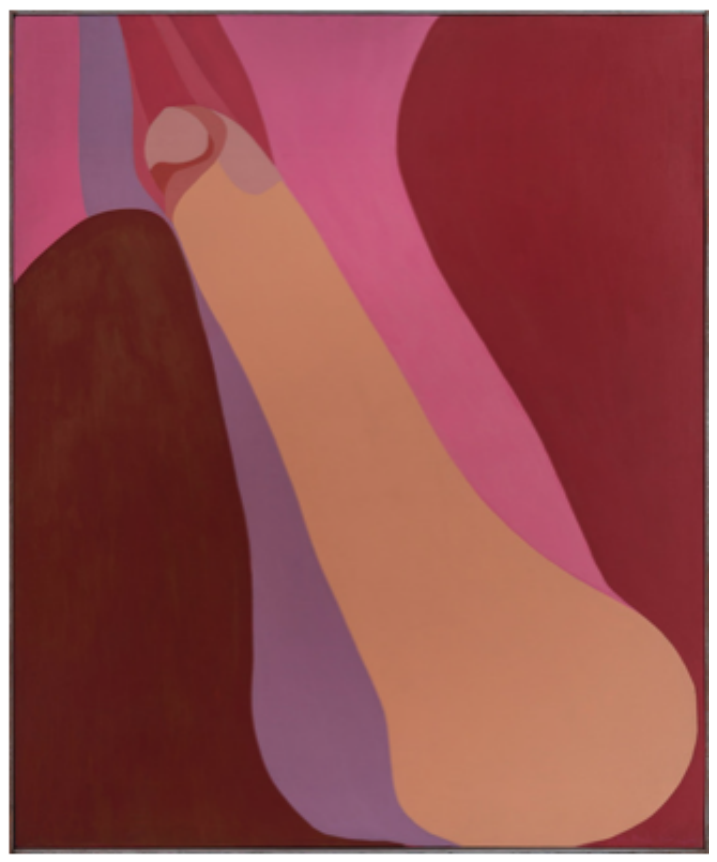

Marta Mijunín, da série Frozen Sex, 1974.

Acrílica sobre tela, 153 x $126 \mathrm{~cm}$. Fonte: Herlitzka + Faria.

\section{Imagem 4 - Sem título}

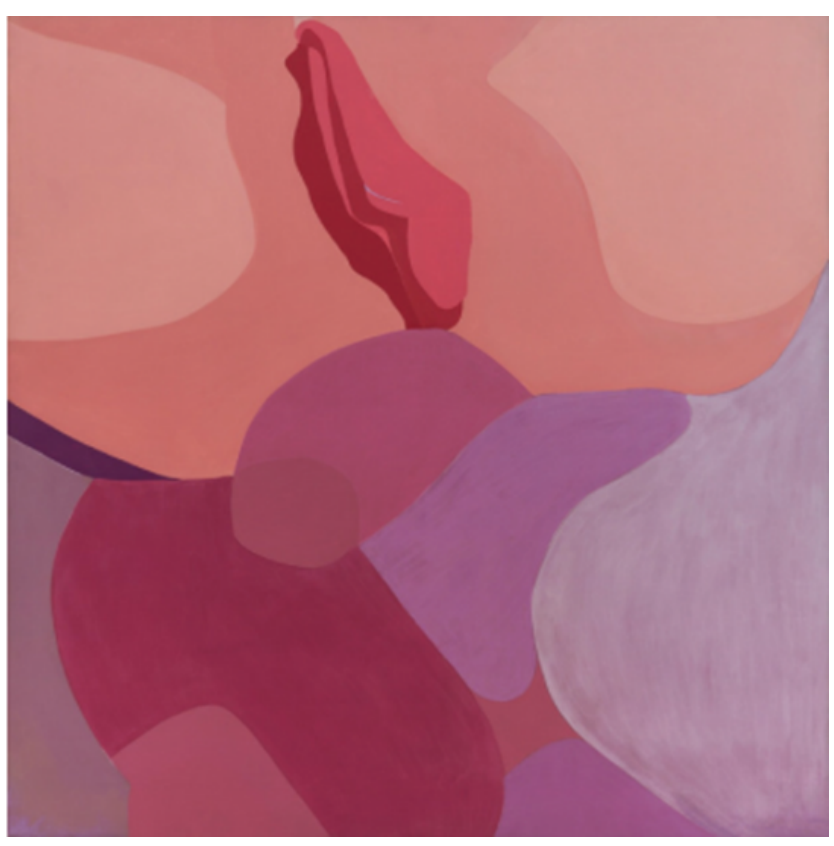

Marta Mijunín, da série Frozen Sex, 1973-1974.

Acrílica sobre tela, 127 x $127 \mathrm{~cm}$. Fonte: Herlitzka + Faria.

\section{Revista Eletrônica da} ANPHLAC

Revista Eletrônica da ANPHLAC, ISSN 1679-1061, № 31, p. 395-419 Ago./Dez., 2021.

http://revista.anphlac.org.br 
A artista, porém, afirma que as obras da série foram produzidas com o intuito de posicionar-se contra a demonização do sexo e do erotismo, buscando dignificar o sexo e marcar-se contra o conservadorismo presente no período. Para realizar as obras, Minujín percorreu sex shops, cabarés, festas e cinemas pornôs de Washington buscando captar a energia dos lugares, utilizando como modelo para as pinturas o seu próprio corpo e o de seu marido (MINUJÍN, 2018, s/n). A reprodução do erótico feita por uma mulher, que usa o próprio corpo como modelo, afirma, assim, a posição da mulher como detentora de seus desejos, seu corpo e sua sexualidade, e marcando-se contra as políticas conservadoras e as noções aceitas de feminilidade, como também ocorre com Teresinha Soares.

Marta Minujín e Teresinha Soares, assim como diversas outras artistas do período, apresentaram, assim, o corpo nu e órgãos sexuais como ferramenta de crítica, mas também de empoderamento. No contexto emancipatório da chegada da pílula anticoncepcional, da revolução sexual e da possibilidade do sexo voltado somente ao prazer, muitas artistas do período defenderam o direito feminino ao prazer erótico e denunciaram a representação sexualizada da mulher na mídia e na arte. Elas pretendiam "usurpar, minar ou sabotar a escopofilia do olhar masculino, voltando seu próprio olhar para o corpo masculino ou feminino" (MINIOUDAKI, 2010, p. 141), invertendo a dinâmica estabelecida até então, que colocava as mulheres como objetos de desejo e não como sujeitos desejantes. O erótico não apareceria, portanto, em suas obras, como lugar das fantasias sexuais masculinas, mas como um espaço de exploração e autoafirmação feminina. É a mulher, agora, que olha e representa o corpo, sendo que as artistas entendiam o "corpo erótico feminino como um instrumento radical do prazer sexual e da liberação feminina” (MINIOUDAKI, 2010, p. 143). As mulheres representadas nas obras, assim como as próprias artistas, se apresentavam como sexualmente conscientes, no controle de suas vidas, seus corpos e seus desejos.

Minujín apresentou oito telas da série Frozen Sex na galeria Arte Nuevo, em Buenos Aires, em 1973, mas a mostra foi censurada e fechada pela polícia três horas depois da inauguração. De acordo com Lemus, a censura da exposição pode ter ocorrido não somente pelo contexto da implementação de uma legislação mais repressiva no país naquele período, 
mas pelo fato de ter sido uma exposição erótica realizada por uma artista mulher. Para ele, "um primeiro ponto a ter em conta para compreender esta situação é que Minujín é uma mulher, e nestes casos, o grau de censura é sempre outro" (LEMUS, 2018, s/n). A série foi então exposta em 1974 na Hard Art Gallery, em Washington D.C., e só voltou a ser mostrada em Buenos Aires em 2018, em exposição organizada na galeria Herlitzka + Faria.

Além das pinturas e serigrafias, as artistas do período utilizaram objetos, mobiliário, instalações e ambientes para representar o corpo feminino e discutir questões de gênero, e também para incentivar a participação do público, aspecto importante da vertente pop e da nova figuração dos países sul-americanos. A artista peruana Teresa Burga está entre as artistas da época que criaram ambientes que representavam o ambiente doméstico e a figura feminina. Nascida em 1935, em Iquitos, Burga teve seu trabalho marginalizado por um longo período, lentamente voltando a ganhar reconhecimento nos últimos anos, como aponta Miguel Lopez, “depois de estar fora do circuito de arte - e da própria história da arte - por mais de vinte e cinco anos" (LÓPEZ, 2014, p. 47).

Burga, assim como Minujín, se identificou com o rótulo pop. Muitas de suas obras questionavam os estereótipos de gênero e o lugar social da mulher, discutindo ainda a representação da figura feminina como objeto da projeção masculina, em um país e em uma época na qual a política e o domínio público eram ocupados pelos homens. Em 1981, Burga encerrou sua carreira nas artes visuais, assim como outras artistas da época, devido à "dificuldade em obter apoio financeiro para as suas iniciativas, bem como o pouco interesse institucional em suas metodologias experimentais" 9 (LÓPEZ, 2014, p. 48), passando a trabalhar na área de administração pública. A artista ficou sem exibir de 1981 até o início dos anos 2000, quando seu trabalho foi retomado por curadores sul-americanos em um movimento de releitura da arte conceitual produzida nesse espaço.

A discussão a respeito da objetificação da figura feminina e da posição da mulher na sociedade apareceu em sua exposição intitulada Objetos, realizada em 1967 na Galería Cultura y Libertad, em Lima, onde apresentou a mulher inserida em ambientes domésticos

\footnotetext{
${ }^{9}$ Tradução da autora, no original: “dificultad para conseguir apoyo económico para sus iniciativas, así como el poco interés institucional para sus metodologías experimentales” (LÓPEZ, 2014, p.48) 
construídos com uma estética pop, como banheiro, quarto e boudoir. O ambiente do quarto na exposição foi montado com cortinas nas paredes, um tapete no chão, e uma cama no centro do espaço, na qual havia a figura de uma mulher seminua, vestindo apenas uma calcinha, com sua cabeça pintada na cabeceira da cama, os braços e seios nos travesseiros, e o restante do corpo no colchão [imagem 5]. O corpo seminu da mulher esticado na cama, com os braços caídos, não aparecia como uma imagem de afirmação da sexualidade e do prazer feminino, como nas obras anteriores de Soares e Mijunín, mas como um corpo passivo e sujeitado, em uma crítica à invisibilização feminina e seu aprisionamento ao espaço doméstico.

\section{Imagem 5 - Sem título}

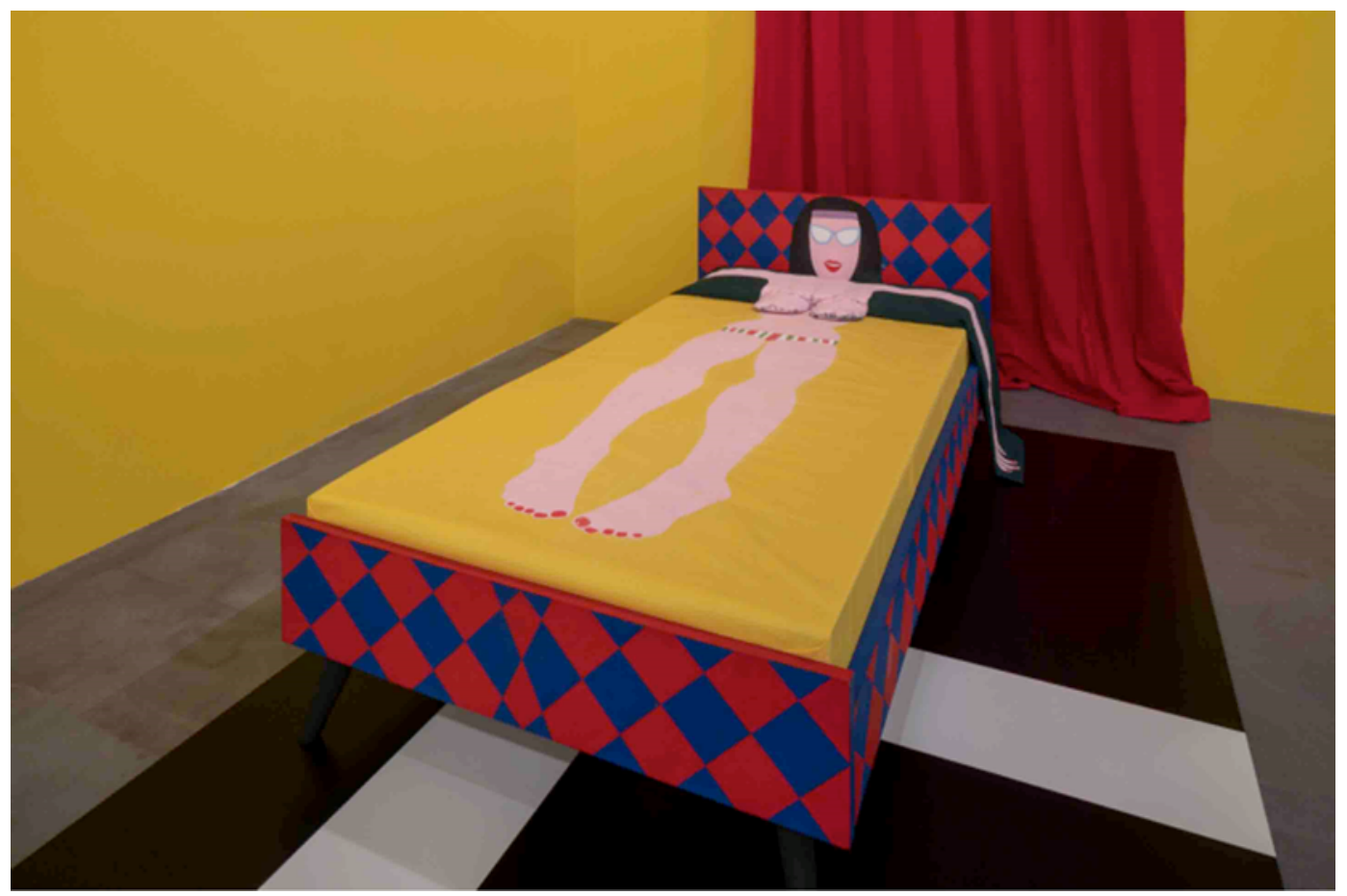

Teresa Burga, 1967. Técnica mista, dimensões variáveis. Obra restaurada em 2007.

O corpo foi representado de acordo com os ideais de beleza da época, largamente anunciados pelos meios de comunicação: ela é magra, tem os seios grandes, que estão em alto relevo, as unhas dos pés e das mãos pintadas de vermelho, e a boca com um batom na mesma 
cor. Ela usa ainda uns óculos, que são representados de uma maneira que não potencializa o olhar dessa mulher, mas que, de certa maneira, o apaga e esvazia. Ela não possui um olhar ativo ou desafiante que responda ao observador, o que garante, de certa maneira, uma manutenção da ideia do observador, geralmente entendido como masculino, como o detentor do olhar ativo, e da mulher como objeto do olhar. Além disso, a mulher não está simplesmente representada sobre a cama, que aqui aparece como um lugar de submissão, mas ela é a própria cama, o travesseiro, o colchão. Ela aparece, portanto, dissolvida nesse mobiliário, nessa arquitetura, como se fosse parte dele, e se assemelha, ainda, a uma boneca inflável, pousada sobre a cama, aguardando o momento de ser utilizada.

O espaço da casa aparece, aqui, não como um espaço de proteção, mas de repressão, aprisionamento e submissão, no qual a mulher é oprimida e objetificada de diferentes maneiras. Na obra de Burga, assim como em produções de outras artistas da época, as hierarquias entre os corpos e os objetos se dissolvem, e a mulher aparece no espaço como objeto de decoração ou manutenção do lar, ou como objeto de desejo e fetiche. O espaço íntimo do lar é representado, nesse contexto, não como um local de proteção, mas como um espaço de aprisionamento e opressão. O espaço da casa aparece, ainda, "como um lugar onde os bens materiais eram colocados em exibição, sancionando o status do proprietário" (FRIGERI, 2018, p. 97) ${ }^{10}$, incluindo o próprio corpo da mulher entre esses bens. A casa aparece, portanto, como o espaço restrito do feminino e como "um alvo principal do consumismo cotidiano e das ficções patriarcais" (MINIOUDAKI, 2015, p. 79) ${ }^{11}$.

Os trabalhos apresentados na exposição, assim como outros produzidos por Burga na época, se inspiravam em propagandas de produtos para o lar, que mostravam recorrentemente mulheres no espaço doméstico, hora representadas no papel de dona de casa servil, mesclada em meio ao mobiliário, hora sexualizadas e em poses de submissão. Assim, se as mulheres de classe média dos anos 1960, dentre elas as artistas, já usufruem de uma liberdade muito maior

\footnotetext{
${ }^{10}$ Tradução da autora, no original: "the home as a place where material goods were put on display sanctioning the homeowner's status" (FRIGERI, 2018, p. 97)

${ }^{11}$ Tradução da autora, no original: "and a primary target of everyday consumerism and patriarchal fictions" (MINIOUDAKI, 2015, p. 79)
} 
de circulação e acesso aos espaços da modernidade, entretanto, como ressalta Margareth Rago,

\begin{abstract}
A invasão do cenário urbano pelas mulheres (...) não traduz um abrandamento das exigências morais (...) Ao contrário, quanto mais ela escapa da esfera privada da vida doméstica, tanto mais a sociedade burguesa lança sobre seus ombros o anátema do pecado, o sentimento de culpa diante do abandono do lar, dos filhos carentes, do marido extenuado pelas longas horas de trabalho... Afinal, a preocupação com sua educação visa prepará-la não para a vida profissional, mas sim para exercer sua função essencial: a carreira doméstica. (RAGO, 1985, p. 62).
\end{abstract}

Assim, se as mulheres dos anos 1960 gozavam de uma maior liberdade para percorrer a cidade, com um número cada vez maior de mulheres de classe média inseridas no mercado de trabalho, essa possibilidade de circulação e de vivência fora do lar não significou uma libertação do espaço doméstico, que continuou como uma responsabilidade da mulher. As propagandas da época reforçavam essa conexão entre o doméstico e o feminino, representando largamente a mulher no espaço do lar e anunciando produtos que tornariam mais eficiente o cuidado com a casa, com o marido e com os filhos. Nesses anúncios, a mulher aparecia constantemente mesclada ao mobiliário e aos objetos da casa, ela própria objetificada e desindividualizada. Como ressalta Vania Carneiro de Carvalho,

O fenômeno de despersonalização feminina na sua dimensão material e cotidiana, ou seja, naquele espaço onde a mulher diariamente empreende ações automatizadas e mediadas pelos objetos da casa, parece-nos estratégico para transformar a percepção social da mulher como acessório doméstico em algo extraordinariamente familiar. (CARVALHO, 2008, p. 87).

Os ambientes de Burga, assim, "teatralizavam sarcasticamente as relações de poder em lugares privados familiares, (...) bem como em lugares públicos” (LÓPEZ, 2014, p. 55) e, ao mesclar a representação feminina com os mobiliários, ela apontava, portanto, para a objetificação do corpo e da figura feminina pela mídia e pela sociedade em geral. É interessante ressaltar, porém, que, de acordo com Miguél Lopez, a exposição Objetos, de Burga, foi discutida pela mídia no período em termos de suas inovações formais e relações com a pop, sem que fossem abordadas as questões de gênero presentes em suas produções. 
Dada a inexistência de discussões sobre gênero na cena artística local dos anos 1960, não é de se admirar que tenha havido pouca atenção (...) da imprensa sobre os aspectos mais críticos dos ambientes de Burga. Nenhuma crítica aludia ao sistema de papéis sexuais e referenciais tradicionais (mãe, esposa, trabalhadora) parodiados pela artista, e da mesma forma há uma ausência de reflexão sobre a dificuldade das mulheres de alcançarem a autonomia em uma sociedade que era política, jurídica, social e economicamente estruturada para assegurar a dependência, a submissão e a desigualdade de gênero. (LÓPEZ, 2014, p. 56) ${ }^{12}$.

Assim, se hoje identificamos o caráter crítico e contestador dessas produções, no contexto e espaço em que Burga vivia, no qual as questões femininas ainda não eram identificadas e discutidas de maneira recorrente pela arte e pela mídia, esse caráter de crítica ao lugar social da mulher, presente em sua produção, não foi evidenciado. ${ }^{13}$

Além de Teresa Burga, Teresinha Soares também utilizou a cama como ferramenta para discutir a questão da objetificação da mulher e das noções de feminilidade. Na obra Ela me deu bola (Camas), de 1970, exibida na exposição coletiva Objeto e Participação, no Palácio das Artes, em Belo Horizonte, também em 1970, três camas de madeira apareciam lado a lado, com colchões pintados com as cores de três times de futebol - a seleção brasileira, o Flamengo e o Atlético Mineiro [imagem 6]. Nas molduras das camas havia abas de madeira que se moviam e que, quando fechadas pelo público, formavam silhuetas femininas nuas em poses sensuais. Na parte interior das abas havia, pintadas em cores fortes e vibrantes, imagens de ídolos do futebol, entre eles o jogador Pelé.

\footnotetext{
${ }^{12}$ Tradução da autora, no original: "Given the nonexistence of discussions about gender in the local art scene of the 1960s, no wonder there was little attention (...) from the press concerning the most critical aspects of Burga's environments. No reviews alluded to the system of sexual roles and traditional frames of reference (mother, wife, worker) parodied by the artist, and likewise there is an absence of any reflection on the difficulty for women to achieve autonomy in a society that was politically, legally, socially, and economically structured to assure the dependence, submission, and inequality of gender" (LÓPEZ, 2011, p. 93).

${ }^{13}$ Em outros espaços da América do Sul, porém, parte da crítica já começa a identificar a preocupação com as questões de gênero que aparecem em algumas obras. Frederico Morais ressalta em uma matéria intitulada "A mulher na Bienal de São Paulo", para o Diário de Notícias (Rio de Janeiro), em 1967 (mesmo ano da exposição de Burga), que "a mulher está se considerando como tema, se questionando". Além disso, já em 1965, a artista brasileira Mona Gorovitz discute a questão feminina em seu texto para o catálogo da exposição Proposta 65, intitulado Why the Feminine. O texto de Gorovitz fala da representação de temas importantes para as mulheres do período em obras de artistas como Marta Minujín, Dalila Puzzovio, Niki de Saint Phalle e Marisol Escobar, estabelecendo uma relação entre elas.
} 
A obra abordava, assim, representações aceitas da feminilidade e da masculinidade. De um lado, as abas representavam o futebol, considerado na época como um espaço exclusivamente masculino, com seus ídolos celebrados como heróis nacionais. De outro, apresentavam a figura da mulher, normalmente representada em conexão com o espaço doméstico, representado pelas camas, ou hipersexualizada e objetificada, em poses sensuais, como as retratadas na obra.

\section{Imagem 6 - Ela me deu bola (Camas)}

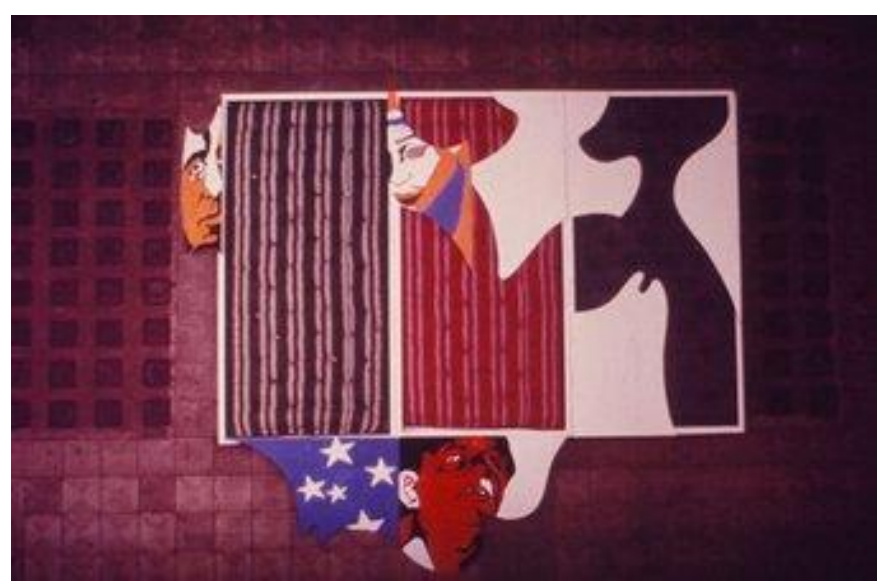

Teresinha Soares, 1970.

Pintura sobre compensado de madeira, tecido, colchões e dobradiças, dimensões variáveis.

Essas representações se relacionam ainda a uma imagem do Brasil que é disseminada no exterior - o futebol, com seus jogadores conhecidos mundialmente, e o estereótipo da mulher brasileira sensual, erotizada, com seu corpo anunciado e muitas vezes comercializado. Além disso, a obra convidava o público a participar, algo que se tornou cada vez mais presente na produção de Soares, que passou a realizar, nesse período, diversas ambientações e happenings. Posicionada diretamente no chão, a obra só podia ser realmente ativada com a participação do público, que abria e fechava as abas e deitava na cama, estabelecendo contato com o outro em um momento de intimidade. A cama, propícia para esse tipo de interação, 
estava conectada ainda ao interesse dos artistas do período em mostrar as conexões entre a arte e a vida, afinal, como destaca Soares, "a cama é onde você nasce, morre, faz filhos, faz amor, descansa e sonha" (SOARES, 2017, p. 102).

Minujín também produziu diversos ambientes e instalações que utilizavam colchões e camas. Obras como Colchón (Eróticos en tecnicolor) [imagem 7], de 1964, e ¡Revuélquese y viva! ${ }^{14}$ (Role e viva!) [imagem 8], do mesmo ano, foram construídas em tecido preenchido com espuma e pintado em cores fortes, que formavam as listras características dos colchões da época. O uso de colchões, que fazem referência a situações de intimidade, como descanso e sexo, convidava o público a interagir com as obras. Muitas produções de Minujín, assim como as de Teresinha Soares, incentivavam essa participação direta do público e buscavam conectar arte e vida. De maneira muito semelhante a Soares, Minujín destaca que nas camas e "nos colchões passamos mais da metade das nossas vidas. Nascemos, dormimos, fazemos amor, e até nos podem matar" (MINUJíN, 2021, s/n) ${ }^{15}$.

\section{Imagem 7 - Colchón (Eróticos en tecnicolor)}

\footnotetext{
${ }^{14}$ Obra com a qual Minujín g:

15 Tradução da autora, no or dormimos, hacemos el amor,
}

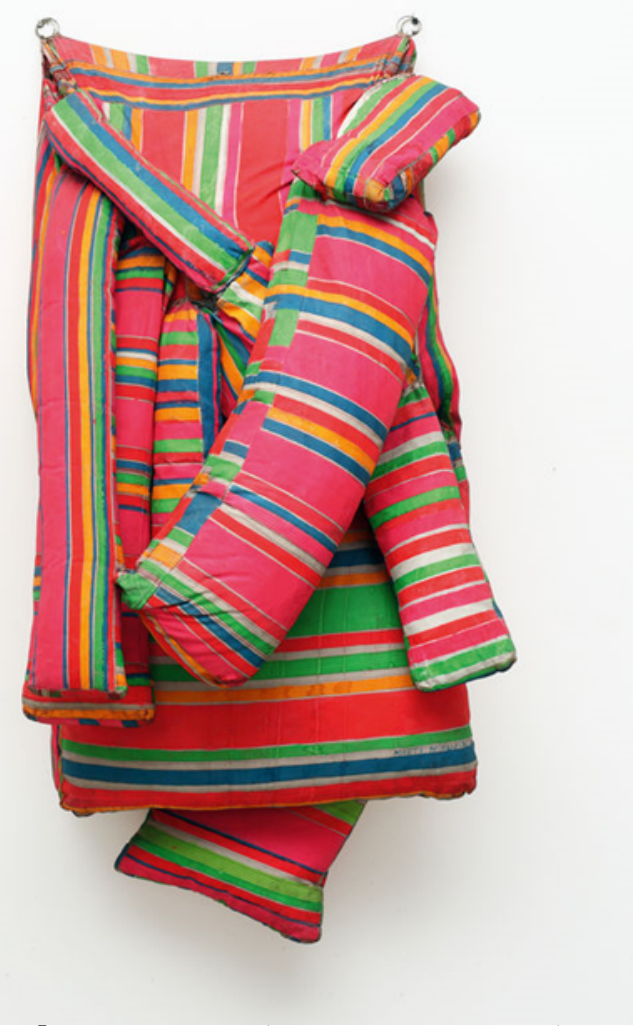


Marta Minujín, 1964. Têmpera sobre tela e fibras têxteis, 150 x 87 x $54 \mathrm{~cm}$. Coleção particular.

\section{Imagem 8 - ¡Revuélquese y viva!}

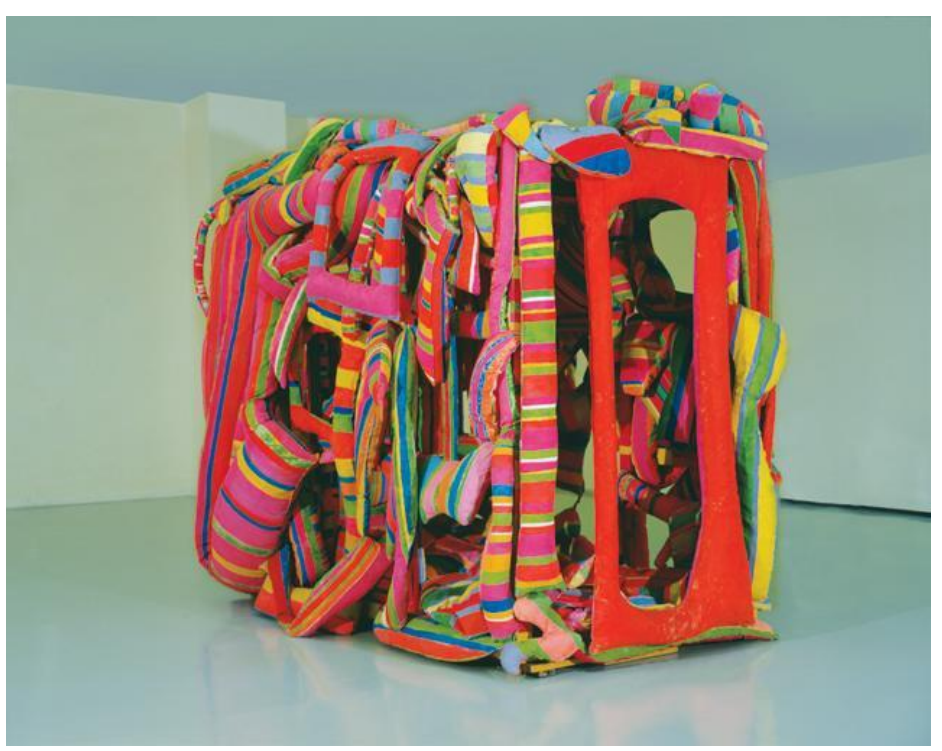

Marta Minujín, 1964. Madeira e têmpera sobre tela, dimensões variáveis. Coleção particular.

A questão do erotismo e da liberdade sexual aparece já nos títulos das obras. Em Colchón (Eróticos en tecnicolor), a artista faz referência à técnica que permitia filmar em cores (Technicolor), aplicada a partir da década de 1910, e que atingiu seu ápice nos anos 1950 e 1960, utilizando cores fortes e saturadas. A obra não representa um corpo de maneira 
figurativa, como nas camas de Burga e Soares, mas os volumes que saem do colchão remetem a membros do corpo e podiam aludir, de acordo Maria José Herrera, "a dois corpos durante um ato sexual"16 (HERRERA, 2010, p. 9). Ainda para Herrera, "à provocação do tema se somava a promessa da fidelidade do technicolor" ${ }^{\prime 17}$ (HERRERA, 2010, p. 9) - era mais que sexo e erotismo, era sexo e erotismo a cores, mais intenso, e mais "real".

Na obra ;Revuélquese y viva!, o título é também sugestivo. Como ressalta Herrera, ao incitar o público a "chafurdar e viver", o título pode ser considerado provocador também pelo “uso da linguagem popular" (HERRERA, 2010, p. 9), como uma referência ao lunfardo, espécie de gíria ou dialeto argentino usado de forma recorrente nas letras dos tangos. Além disso, a obra formada por vários fragmentos de colchões, que contava com música no ambiente, possuía uma entrada na cor vermelha que aludia ao formato de uma vagina. Por meio dessa abertura, o público penetrava a instalação e podia deitar e interagir em um espaço de intimidade. A obra se apresentava, assim, como um espaço de afirmação da liberdade sexual, defendendo uma exploração sem culpa do desejo e da sexualidade. Esse tipo de produção, que remete ao corpo feminino e ao sexo livre, realizada por uma mulher e nesse período, possuía, assim como aquelas de Burga e de Soares, uma potência extremamente transgressora.

Os temas relacionados à vivência cotidiana da mulher e seus novos embates no mundo moderno foram, assim, explorados pelas artistas da pop e da nova figuração no Brasil, Argentina e Peru, em obras que refletiram sobre a própria formação das subjetividades femininas em seu período e espaço de produção. As obras de algumas dessas artistas foram produzidas com um claro teor contestatório e crítico à condição da mulher no período. Outras, mais voltadas ao registro do cotidiano, se não foram construídas conscientemente como uma crítica, não deixaram de estar conectadas às preocupações e problemáticas femininas da época, abordadas pelo movimento feminista e também pela arte feminista a partir dos anos 1970. Podemos pensar, ainda, que essas obras não somente retrataram as questões

\footnotetext{
16 Tradução da autora, no original: “a dos cuerpos durante un acto sexual” (HERRERA, 2010, p. 09).

17 Tradução da autora, no original: "A la provocación del tema se le agregaba la promesa de fidelidade del technicolor" (HERRERA, 2010, p. 09).
} 
relacionadas à vivência e à subjetividade femininas, mas que possuem a potência, elas mesmas, de impactar na formação e transformação dessas subjetividades. Afinal, como ressalta Griselda Pollock, a arte "é uma das práticas sociais por meio da qual se constroem, reproduzem e se redefinem visões particulares do mundo, definições e identidades (...)" (POLLOCK, 2013, p. 75).

Apesar de um aumento recente no número de pesquisas dedicadas à produção de mulheres artistas sul-americanas e à produção sul-americana associada à pop, ainda são escassos os trabalhos dedicados a analisar a produção feminina sul-americana associada ao fenômeno da pop e da nova figuração, entendida enquanto um grupo, sendo que essa produção foi apenas parcialmente reconhecida até o momento. O trabalho pretende, assim, contribuir para a expansão do cânone da história da arte e para reflexões a respeito dos contextos e estruturas responsáveis pela marginalização de um grande número de artistas durante a formação desse cânone. Teresinha Soares, Marta Minujín e Teresa Burga produziram ativamente nos anos 1960 e 1970 e suas obras tiveram grande importância no contexto das vanguardas da época. Mesmo em um contexto político marcado por repressão e conservadorismo, essas artistas criaram obras transgressoras que questionavam muitas das noções e estereótipos relacionados à figura feminina no período. Suas obras, contestatórias e potentes, são relevantes para pensarmos a condição feminina nos anos 1960 e 1970 e nos ajudam ainda a analisar o espaço das mulheres na sociedade atual.

\section{Referências bibliográficas}

BARNITZ, Jacqueline. A Latin Answer to Pop. Arts Magazine, jun. 1966, p. 36-9.

BUTLER, Connie. Monumentos caídos: o continuum feminista. In: FAJARDO-HILL, Cecilia; GIUNTA, Andrea. Mulheres Radicais: arte latino-americana, 1965-1980. São Paulo: Pinacoteca de São Paulo, 2018.

CARVALHO, Vania Carneiro de. Gênero e artefato: o sistema doméstico na perspectiva da cultura material. São Paulo, Editora da Universidade de São Paulo/FAPESP, 2008. 
FAJARDO-HILL, Cecilia. A arte erótica singular de Teresinha Soares. In: PEDROSA, Adriano; MOURA, Rodrido (Org.). Quem tem medo de Teresinha Soares? São Paulo: MASP, 2017.

FRIGERI, Flavia. Pop Art. Londres: Thames \& Hudson, 2018.

GIUNTA, Andrea. A virada iconográfica: a desnormalização dos corpos e sensibilidades na obra de artistas latino-americanas. In: FAJARDO-HILL, Cecilia; GIUNTA, Andrea. Mulheres Radicais: arte latino-americana, 1965-1980. São Paulo: Pinacoteca de São Paulo, 2018.

GREET, Michele. Mapping cultural Exchange: Latin American artists in Paris between wars. In: KAUFMANN, Thomas DaCosta, DOSSIN, Catherine; JOYEUX-PRUNEL, Béatrice (eds.) Circulations in the Global History of Art. Burlington: Ashgate, 2015.

HERRERA, Maria José. POP! La consagración de la primavera. Buenos Aires: Fundación OSDE, 2010.

HOUBRE, Gabrielle. Um sexo impensável: A identificação dos hermafroditas na França do século XIX. Tradução de Débora El-Jaick de Andrade. Espaço Plural, v. X, n. 21, 2009, p. 20-32.

LEMUS, Francisco. Marta Minujín: Frozen Sex. Artshock, 2018.

LÓPEZ, Miguel Ángel. Conceptualismos fallidos: Extravíos estéticos y pulsiones políticas en la obra de Teresa Burga. In: LÓPEZ, Miguel Ángel; TARAZONA, Emilio. Teresa Burga. Informes. Esquemas. Intervalos. Lima: ICPNA, 2011.

LÓPEZ, Miguel Ángel. Teresa Burga: Desplegando el cuerpo (social) femenino. Art Journal: v. 73, 2014.

MARTINS, Heitor; PEDROSA, Adriano. Teresinha Soares no MASP. In: PEDROSA, Adriano; MOURA, Rodrigo (Org.). Quem tem medo de Teresinha Soares? São Paulo: MASP, 2017.

MELENDI, Maria Angélica. Para construir novas casas e desconstruir velhas metáforas de fundação. In: FAJARDO-HILL, Cecilia; GIUNTA, Andrea. Mulheres Radicais: arte latino-americana, 1965-1980. São Paulo: Pinacoteca de São Paulo, 2018.

MINIOUDAKI, Kalliopi. Other(s') Pop: The Return of the Repressed of Two Discourses. In: MATT, Gerald; STIEF, Angela. Power Up - Female Pop Art. Viena: Kunsthalle Wien, 2010.

MINIOUDAKI, Kalliopi. Feminist Eruptions in pop, Beyond Borders. In: MORGAN, Jessica; FRIGERI, Flavia. The World Goes Pop. New Haven: Yale University Press, 2015. 
MINUJíN, Marta. Una noche de frío en París: Marta Minujín vuelve a exponer colchones y explica de dónde salieron. Entrevista concedida a Ignacio Di Tullio. Clarín, Buenos Aires, 08 de maio de 2021. Disponível em: https://www.clarin.com/cultura/color-color-color-marta-minujin-volvio-colchones-version-flu or $0 \mathrm{~m} 0 \mathrm{ZrmAwCn} . \mathrm{html}$. Acesso em: 01 de junho de 2021.

MINUJÍN, Marta. Marta Minujín: "Los órganos sexuales son tan importantes como la cara". Entrevista concedida a Mercedes Pérez Bergliaffa. Clarin, Buenos Aires, 15 de maio de 2018. Disponível

em: https://www.clarin.com/cultura/marta-minujin-organos-sexuales-importantes-cara 0 HyESh3 ORf.html. Acesso em: 01 de junho de 2021.

ORVIG, Helen. También antes hubo algo. In: CEVASCO, Gaby (ed.). 25 años de feminismo en el perú: Historia, confluencias y perspectivas. Lima: Centro de la Mujer Peruana Flora Tristán, 2004.

POLLOCK, Griselda. Modernidad y espacios de la feminilidade. In: Vision y diferencia: feminismo, feminidad e historias del arte. Buenos Aires: Fiordo, 2013

RAGO, Margareth. Do cabaré ao lar. A utopia da cidade disciplinar. Brasil 1890-1930. São Paulo: Paz e Terra, 1985.

SOARES, Teresinha. O artista e a arte são um, não se dividem. Entrevista de Teresinha Soares a Rodrigo Moura e Camila Bechelany, Belo Horizonte, 21 dez. 2016. In: PEDROSA, Adriano; MOURA, Rodrigo (Org.). Quem tem medo de Teresinha Soares? São Paulo: MASP, 2017.

STIEF, Angela. Power Up - Back to the Future. In: MATT, Gerald; STIEF, Angela. Power Up - Female Pop Art. Viena: Kunsthalle Wien, 2010.

TELES, Maria Amélia de Toledo. Breve história do feminismo no Brasil e outros ensaios. São Paulo, Editora Alameda, 2017.

TRIZOLI, Talita. Atravessamentos Feministas: um panorama de mulheres artistas no Brasil dos anos 60/70. Tese (Doutorado). Faculdade de Educação, Universidade de São Paulo: São Paulo, 2018.

VICENTE, Filipa Lowndes. A arte sem história. Mulheres e cultura artística (Séculos XVIXX). Lisboa: Babel, 2012. 